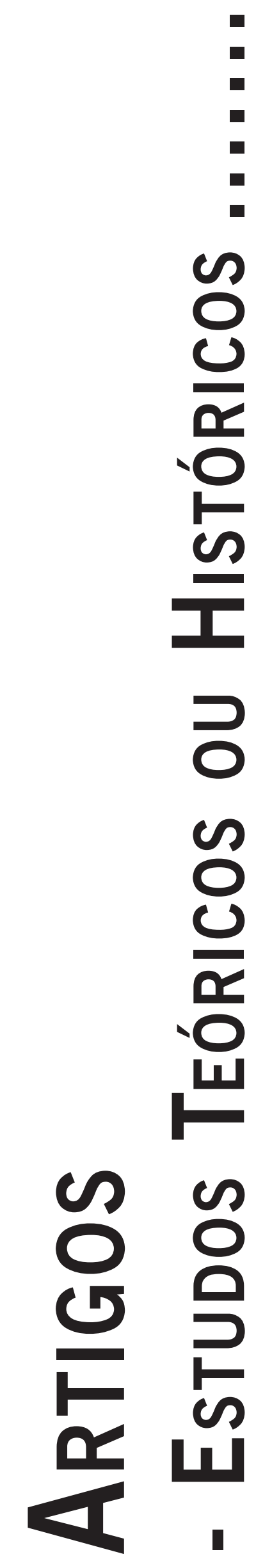




\title{
DIÁLOGO ENTRE ANÁLISE DE CONTEÚDO E MÉTODO FENOMENOLÓGICO EMPÍRICO: PERCURSOS HISTÓRICOS E METODOLÓGICOS
}

\author{
Dialogue Between Contend Analysis and Empirical Phenomenological Method: \\ Methodological and Historical Paths \\ Diálogo Entre el Análisis de Contenido y Método Fenomenológico Empírico: \\ Caminos Históricos y Metodológicos
}

Paulo Coelho Castelo Branco

\begin{abstract}
Resumo: Este artigo realiza um estudo comparativo entre duas perspectivas de métodos qualitativos - a análise de conteúdo (AC) e o método fenomenológico empírico (MFE). O intuito de comparar ambos os métodos ocorre mediante o argumento de que eles surgiram historicamente no mesmo Zeitgeist de debates metodológicos, oriundos da Escola de Chicago. Esta representou uma corrente de contendas sobre a elaboração de perspectivas metodológicas de pesquisa qualitativa, em alternância às clássicas e instituídas vertentes de pesquisa quantitativa, respaldada pelo paradigma positivista. Esquematizam-se os percursos históricos e os procedimentos da AC de Laurence Bardin e do MFE de Amedeo Giorgi. Discutem-se os seguintes pontos de interlocução: (1) a ênfase na ação humana investida de significados como crítica à neutralidade científica; (2) a vinculação filosófica; (3) a forma de concepção e tratamento do objeto de estudo; (4) a questão do primeiro contato com o material transcrito; (5) a divisão do texto em unidades analíticas; e, (6) o anteparo empírico que norteia a categorização. Conclui-se que o campo das Ciências Sociais e Humanas, no qual a Psicologia se insere, é constituído por uma diversidade de perspectivas metodológicas que requer constantemente revisões, elucidações e delimitações sobre os seus modos de fazer pesquisa.
\end{abstract}

Palavras-chave: História; Metodologia; Pesquisa qualitativa; Psicologia.

\begin{abstract}
This article presents a comparative study between two perspectives of qualitative methods - content analysis (CA) and empirical phenomenological method (EPM). The purpose of comparing both methods is due to the argument that they have emerged historically in the same Zeitgeist of methodological discussions, coming from the Chicago School. This school represented a stream of debates about the development of methodological perspectives of qualitative research, in contrast with classical and already consolidated branches of the quantitative research, supported by the positivist paradigm. The historical paths and the procedures of CA of Laurence Bardin and the EPM of Amedeo Giorgi are outlined. The following points of dialogue are discussed: (1) emphasis on human action invested with meaning as a critique to scientific neutrality; (2) linking philosophical; (3) ways of conception and treatment of the object of study; (4) the question about the first contact with the transcribed material; (5) division of text in analytic units; and (6) the empirical shield that guides the categorization process. One concludes that the field of human and social sciences, where psychology is inserted, comprises a variety of methodological perspectives that require constant revisions, clarifications and delimitations on their ways of doing research.
\end{abstract}

Keywords: History; Methodology; Qualitative research; Psychology.

Resumen: Este artículo presenta un estudio comparativo entre dos perspectivas de los métodos cualitativos - el análisis de contenido (AC) y el método fenomenológico empírico (MFE). La comparación se produce mediante el argumento de que estos métodos han surgido históricamente en el mismo Zeitgeist metodológico, procedente de la Escuela de Chicago. Esta ha representado una línea de contiendas sobre el desarrollo de enfoques metodológicos para la investigación cualitativa, en alternancia a las instituidas vertientes de la investigación cuantitativa, apoyada por el positivismo. Se planean los trayectos históricos y los procedimientos de AC de Laurence Bardin y del MFE de Amadeo Giorgi. Se discuten los siguientes puntos de interlocución: (1) el énfasis en la acción humana investida de sentido como una crítica de la neutralidad científica; (2) el enlace filosófico; (3) la forma de concepción y tratamiento del objeto de estudio; (4) la cuestión del primer contacto con el material transcrito; (5) la división del texto en las unidades de análisis; (6) la protección empírica que se orienta la categorización. Se concluye que las Ciencias Sociales y Humanas, donde se encuentra la Psicología, es compuesta por una diversidad de perspectivas metodológicas que constantemente pide aclaraciones y límites en su forma de hacer investigación.

Palabras clave: Historia; Metodología; Investigación cualitativa; Psicología. 


\section{Introdução}

Este estudo objetiva esboçar um ensaio teórico e comparativo entre duas perspectivas de métodos qualitativos - a análise de conteúdo (AC) e o método fenomenológico empírico (MFE). Para tanto, pretende-se elucidar os aspectos históricos que possibilitaram a emergência de ambos os métodos de pesquisa. $\mathrm{O}$ intuito de realizar tal comparação ocorre pelo argumento de que a AC e o MFE surgiram no mesmo Zeitgeist estadunidense de debates metodológicos sobre a criação de modelos de pesquisa qualitativa em Ciências Sociais e Humanas. O termo Zeitgeist alude a um contexto científico que afeta a cultura e a preocupação intelectual de um determinado período histórico (Penna, 2000). Considera-se, pois, que os referidos métodos respondem de modo distinto à mesma discussão iniciada pela Escola de Chicago e difundida em outras universidades.

A despeito de a AC e do MFE, atualmente, possuírem diversas variações em suas aplicações, foram escolhidos Laurence Bardin e Amedeo Giorgi como eixos de referência para concretizar a interlocução metodológica. O motivo para tal eleição ocorre mediante o argumento de que as perspectivas de Bardin (1977/2011) e Giorgi (1997/2008) se popularizaram e se tornaram amplamente utilizadas, ou mencionadas, em diversas produções teóricas sobre pesquisas empíricas vinculadas à Psicologia (Hycner, 1985; Holanda, 2006; Andrade \& Holanda, 2010) e outras áreas, como a Enfermagem (Rocha \& Deusdará, 2005; Caregnato \& Mutti, 2006; Oliveira, 2008) e a Administração (Boava \& Macedo, 2011).

Destarte, procede-se da seguinte lógica expositiva. Apresenta-se o Zeitgeist da Escola Chicago em suas principais contendas metodológicas. Em seguida, demarcam-se as principais bases históricas da AC, de modo a elucidar sucintamente o seu desenho metodológico, segundo Bardin. Posteriormente, repete-se o procedimento anterior em relação ao MFE, de forma a expor o seu plano metodológico conforme Giorgi. Finalmente, são confrontados os dois métodos para indicar alguns pontos de entendimento que os aproximam e distanciam.

\section{Discussões e perspectivas metodológicas da Escola de Chicago}

Quando se faz referência a Escola de Chicago, urge esclarecer que o termo Escola diz respeito a um agrupamento de pesquisadores que, malgrado expressem pensamentos distintos, compartilham um denominador comum em relação a determinado assunto (Penna, 2001). O vocábulo Chicago acena para uma adjacência onde ocorreram as principais querelas sobre esse assunto. A Escola de Chicago, destarte, representou uma tendência de contendas sobre a elaboração de perspectivas metodológicas de pesquisa qualitativa, em alternância às clássi- cas e instituídas vertentes de pesquisa quantitativa, respaldada por delineamentos experimentais resguardados ao paradigma positivista de ciência.

Com investimentos privados (provenientes da Fundação Rockfeller) e governamentais (oriundos do Governo do Estado de Illinois), no início do século XX, a Universidade de Chicago foi palco de amplo desenvolvimento em pesquisas sociais, psicológicas e antropológicas (Vidich \& Lyman, 2003/2006). Em decorrência desse mote científico, houve aprofundamento de diversas teorias e práticas nessas áreas. Cabe ressaltar que o programa de Psicologia da referida Universidade era alocado no Departamento de Ciências Sociais e Antropologia (Rogers, 1951/1992), o que implicou estudo do comportamento e da personalidade, mediante seus aspectos psicológicos, sociais e culturais.

No campo da Psicologia (Heidbreder, 1933/1981; Marx \& Hilix, 1963/1976; Schultz \& Schultz, 1972/2007), mencionam-se os trabalhos de John Dewey (1859-1952) e James Angell (1869-1949), que fundaram o Funcionalismo. Posteriormente, John Watson (1878-1958) desenvolveu esse legado sob a égide do Comportamentalismo. Merecem ser mencionados, ainda, os estudos pioneiros de George Mead (1863-1931) em Psicologia Social, as visitas de Wolfgang Köhler (1887-1967) e Kurt Kofka (1886-1941), que apresentaram a Psicologia da Gestalt e algumas contribuições da Fenomenologia para a Psicologia dos EUA, assim como as investigações empíricas de Carl Rogers (1902-1987) sobre os processos de mudança de personalidade em psicoterapia.

No campo da Antropologia (Denzin \& Lincoln, 2003/2006; Vidich \& Lyman, 2003/2006), predominaram investigações qualitativas compreensivas à formação e ao funcionamento dos grupos humanos. Desenvolveram-se, também, estudos de costumes sociais e culturas urbanas, mediante o uso de procedimentos etnográficos. São dignos de destaque, também, os trabalhos de Margareth Mead (1901-1978), Ruth Benedict (1887-1948), Bronislaw Malinowski (1884-1942) e as visitas - com posterior docência - de Clifford Geertz (1926-2006).

Em suma, a questão que permeava as discussões alocadas na Escola de Chicago era: como apreender a verdade sobre o mundo social conforme um rigor de pesquisa válido para as Ciências Sociais? Por um lado, acreditava-se em uma ciência social inspirada em modelos concebidos pelas Ciências Naturais e influenciados pelo Positivismo de Auguste Comte (1798-1857) e a Sociologia de Émile Durkheim (1858-1917). Cabia ao pesquisador observar o mundo social em uma perspectiva neutra e exterior ao seu acontecimento. Havia, pois, uma dicotomia entre contemplação e ação, em que a supremacia do olhar de fora e o controle de variáveis sobre este olhar garantiriam o almejado rigor científico (Pires, 1997/2008). De outra parte, em contraposição ao modelo anterior, a Escola de Chicago questionou a valorização da neutralidade, da observação exterior e da manipulação de variáveis em 
pesquisa. Influenciados pela Sociologia da Marx Weber (1864-1920) e pela Sociofenomenologia de Alfred Schutz (1899-1959), muitos pesquisadores aprofundaram investigações que valorizaram aspectos do senso comum e cotidiano das pessoas (Pires, 1997/2008). Ressalva-se o fato de que nem todos os expoentes da Escola de Chicago se opuseram à neutralidade científica, todavia insistiram “(...) de maneira incisiva na necessidade de levar em conta o ponto de vista dos atores sociais que se pesquisa, sejam eles 'underdogs' ou 'overdogs"'1 (p. 73, grifos do autor).

A Escola de Chicago se destacou pela sua concepção epistemológica no modo de sistematizar e adquirir conhecimento válido nas Ciências Sociais. Considerado um movimento pós-positivista nos EUA, as pesquisas vinculadas a esse grupo empregaram “(...) uma variedade de novas perspectivas qualitativas, interpretativas, incluindo a hermenêutica, o estruturalismo, a semiótica, a fenomenologia, os estudos culturais e o feminismo" (Denzin \& Lincoln, 2003/2006, p. 17). Foram desenvolvidos e combinados métodos de entrevistas com procedimentos observacionais e analíticos de documentos e mídias jornalísticas.

Da segunda metade do século XX em diante, o movimento da Escola de Chicago perdeu força, em decorrência da dispersão dos seus expoentes para outras universidades e em razão da censura acadêmica, para a qual suas pesquisas não eram críticas o suficiente para denunciar os mecanismos sociais de dominação e relações de poder. Desse ensejo, desenvolveram-se algumas perspectivas de análise do discurso (Pires, 1997/2008). A Escola de Chicago, contudo, permanece como fonte de referência histórica na concepção de paradigmas metodológicos qualitativos nas Ciências Sociais, Psicológicas e Antropológicas.

\section{Análise de conteúdo: percursos históricos e meto- dológicos}

\subsection{Percursos históricos}

No recorte da ciência moderna, a análise de conteúdo (AC) foi desenvolvida nos primeiros quarenta anos do século XX, nos EUA. Credita-se a Harold Lasswell (1902-1978) o formato de rigor científico utilizado nas Ciências Sociais. Lasswell foi um cientista político e teórico da comunicação que estudou os efeitos da mensagem no percurso emissor-canal-receptor. Oriundo da Escola de Jornalismo de Columbia, Lasswell ampliou seus estudos sobre propaganda e comunicação de massa na

\footnotetext{
O vocábulo underdog denota uma pessoa/facção minoritária e marginal. O contrário disso se denomina overdog, uma alusão àquela pessoa/facção que subjuga o underdog. Nos EUA, essas locuções são utilizadas em pesquisas qualitativas para aludir investigações com camadas sociais (amostras) marginalizadas ou dominantes (Hammersley, 2000).
}

Universidade de Chicago. O autor desenvolveu um modelo de AC, filiada à ciência social positivista e inspirada pela Psicologia Comportamental e pela análise linguística formal e estrutural (Bardin, 1977/2011). Laswell propôs um padrão de estudo sobre os efeitos da mensagem (o que se comunica) no emissor (quem comunica), no canal (onde se difunde a mensagem emitida pelo emissor) e no receptor (aquele para quem a mensagem é difundida) (Puglisi \& Franco, 2005).

Com efeito, a AC surge com base numa perspectiva funcionalista de estudos sobre as variáveis comunicacionais que afetam o comportamento. Rapidamente, a $\mathrm{AC}$ foi empregada em estudos vinculados à Psicologia Social e à Psicologia Personalista na Universidade de Chicago. Nessa expansão, Bernard Berelson (1912-1979) e Paul Lazarsfeld (1901-1976) (conforme citado por Bardin, 1977/2011) estabeleceram uma definição assertiva sobre a AC daquela época. Na intelecção dos autores, "A análise de conteúdo é uma técnica de investigação que tem por finalidade a descrição objetiva, sistemática e quantitativa do conteúdo manifesto da comunicação" (p. 24).

Nas décadas de 1950-1960, houve muitas discussões sobre os procedimentos da AC. Na Universidade de Chicago, especificamente, aconteceram às reunióes da Social Science Research Council's Committee on Linguistic and Psychology (Worceter, 2001; Sibley, 2001) que debateram, de forma interdisciplinar, outros direcionamentos para o referido método. Tais rumos enfocaram orientações mais qualitativas para a análise de conteúdo (AC), de modo que esse método passou a se configurar como um procedimento empírico de análise de textos que realiza uma ponte entre o formalismo estatístico e a análise qualitativa de materiais textuais (Bauer, 2000/2005).

Muito dessa flexibilidade qualitativa ocorreu mediante as contribuições da clínica psicológica (enviesada pela Psicanálise) que se aliou à clássica contribuição estatística do método. Com isso, a AC deixou de ser apenas descritiva para objetivar a inferência do pesquisador, com base nos indicadores de frequência mostrados no texto (Bardin, 1977/2011). Foi, portanto, da década de 1950 em diante que a influência da Escola de Chicago se tornou mais presente na $\mathrm{AC}$, a qual começou a inserir um delineamento qualitativo em suas investigações e, pela noção de inferência, passou a reconhecer as falácias da neutralidade em pesquisa empírica.

\subsection{Percursos metodológicos}

A formulação expressa a seguir sintetiza as etapas da análise de conteúdo (AC). Ressalta-se que, no Brasil, algumas sequências foram propostas (Puglisi \& Franco, 2005; Oliveira, 2008). Utiliza-se aqui o referencial de Bardin (1977/2011), que estabelece a AC como um procedimento técnico que busca obter inferências objetivas sobre os dados de determinado texto. 
1) Inicialmente ocorre a organização do material a ser analisado, por meio da escolha dos textos a serem submetidos à pesquisa em função do seu objeto de estudo, pergunta-problema, hipóteses e objetivos traçados. Esses componentes serão fundamentais para estabelecer os indicadores na análise do material. A primeira etapa aborda, portanto, o delineamento amostral da AC, assim como ocorre um preparo do material, pela elaboração das perguntas, da entrevista e organização da transcrição. Nesse processo, as hipóteses podem ser refeitas.

2) Exploração do material organizado. Nesta fase, ocorrem os procedimentos de codificação dos dados. Na perspectiva de Bardin (1977/2011), "A codificação corresponde a uma transformação - efetuada segundo regras precisas - dos dados brutos do texto, transformação esta que, por recorte, agregação e enumeração, permite atingir uma representação do conteúdo ou da sua representação" (p. 133).

Estabelece-se, pois, quais serão as unidades de registro (UR) analisadas no texto (palavra, tema ou personagem, por exemplo). As UR são compreendidas em referência ao texto e não além dele. Em seguida, atribui-se, de acordo com o interesse da pesquisa, um valor para cada unidade de registro (UR). Posteriormente, investiga-se a medida de frequência em que cada UR aparece, ou não, no texto. Observa-se que cada UR contém uma mensagem que expressa o modo como a amostra se apresenta. Com as frequências de cada UR suscitadas, realiza-se o trabalho de inferência com suporte nos dados levantados e nos seus valores presentes ou ausentes. Inferir significa manipular uma mensagem explicitada na UR investigada, de modo a atribuir-lhe um sentido de acordo com os interesses da pesquisa. Logo, inferir é interpretar o conteúdo do texto de forma lógica, conforme as UR codificadas e levantadas, em frequência, no texto.

3) Após a conclusão da etapa anterior, entende-se que existem indicadores que permitem a elaboração de categorias. No pensamento de Bardin (1977/2011),

A categorização é uma operação de classificação de elementos constitutivos de um conjunto por diferenciação e, em seguida, por reagrupamento segundo o gênero (analogia), com os critérios previamente definidos. As categorias são rubricas ou classes, as quais reúnem um grupo de elementos (unidades de registro, no caso da análise de conteúdo) sob um título genérico, agrupamento esse efetuado em razão das características comuns desses elementos. (p. 147, grifos da autora)

Agrupar as UR de modo a criar categorias, implica fornecer uma forma consistente e condensada de explicação para os dados da pesquisa. As categorias permitem, consequentemente, uma passagem dos indicadores brutos para os dados organizados, conforme uma lógica explicativa do que foi obtido.
Com efeito, a análise de conteúdo (AC) entende que existe um sentido a ser desvelado e evidenciado em um texto. Isso acontece pela descoberta dos seus conteúdos e estruturas de mensagens que representam uma realidade em si, tangível e comum, isto é, para todos (Bauer, 2000/2005). É importante ressaltar, contudo, que a AC não elabora nenhuma reflexão filosófica sobre o que é a realidade, pois interessa ao método elucidar os significados que as pessoas utilizam na realidade (Bardin, 1977/2011). Considera-se, finalmente, que a AC possibilita uma técnica que estabelece modos de captar as frequências das UR do texto, para ordená-las conforme o entendimento de quem as interpreta. $\mathrm{O}$ fato de os enunciados sobre essa realidade serem constituídos (ordenados, codificados, inferidos e categorizados) pelo pesquisador não sugere a constituição de uma hermenêutica ficcional e artificial, dado que essas interpretações ocorrem mediante uma dimensão tangível e fatual do que é exibido no texto analisado.

\section{Método fenomenológico empírico: percursos histó- ricos e metodológicos}

\subsection{Percursos históricos}

Credita-se a Edmund Husserl (1859-1938) a criação do método fenomenológico. Urge, entretanto, realizar uma distinção entre o método fenomenológico filosófico (MFF) e o método fenomenológico empírico (MFE), para se entender como tal método se insere nas Ciências Sociais e Humanas.

Husserl foi um lógico-matemático que se doutorou em Psicologia, sob a orientação de Carl Stumpf (1848-1936), na Universidade de Halle - Alemanha. Ressalta-se que a migração de Husserl da Matemática para a Psicologia e Filosofia decorreu do seu contato com Franz Brentano (1838-1917), que o indicou para estudar com Stumpf (Penna, 2001). Pode-se encontrar uma sistematização elaborada do MFF publicada na obra Ideias para uma fenomenologia pura e para uma filosofia fenomenológica: introdução geral à fenomenologia pura (Husserl, 1913/2006).

O MFF de Husserl (1913/2006) aborda uma reflexão das “(...) diferentes orientações da consciência, com seus diferentes correlatos objetivos" (p. 139), cuja finalidade visa a compreender como, num determinado momento noético, a consciência atribui sentido ao fenômeno que lhe aparece; e como, num momento noemático, a consciência capta o sentido que o fenômeno já possui e mostra em sua manifestação. Conforme Husserl (1913/2006), o termo reflexão alude a “(...) uma designação para atos nos quais o fluxo de vividos é apreensível e analisável de maneira evidente, com todos seus diversos eventos (momentos de vivido, intentionalia)" (p. 171). Logo, o MFF husserliano propõe uma investigação epistêmica sobre o modo em que a consciência é capaz de conhecer o mundo. 
Em ambos os momentos mencionados ocorre a suspensão fenomenológica (Epoché), uma atitude de retirar de ação (tirar de circuito), durante certo momento, os atos de a consciência julgar (atestar, contestar ou ser indiferente) determinado fenômeno, que pode ser um objeto material, uma pessoa, uma ideia ou um acontecimento. Fenômeno deve ser entendido como tudo aquilo que se mostra (aparece) para a consciência de quem utiliza o método (Husserl, 1913/2006). No momento noético, retira-se de ação os juízos em curso sobre o fenômeno investigado, para permitir o exame de como a consciência do investigador lhe atribui um sentido idiossincrático. No momento noemático, ao contrário do anterior, suspendem-se os pré-conceitos e juízos que o investigador possui idiossincraticamente sobre o fenômeno, com o intuito de captar os sentidos que esse possui em essência e circulam no mundo (Husserl, 1913/2006).

O método fenomenológico filosófico (MFF) surge, portanto, como crítica à influência das Ciências Naturais na Psicologia, que utilizava de métodos positivistas para estudar a consciência, reduzindo-a somente a aspectos objetivos observáveis e passíveis de manipulação experimental em laboratório (Penna, 2001). O MFF demonstra que os fenômenos não existem somente por eles mesmos, independentes de uma dimensão subjetiva, pois há uma consciência que se direciona para eles. Eis o entendimento do que é intencionalidade, o a priori da correlação universal entre consciência e mundo (Goto, 2008).

Com advento da proposta de Husserl, muitos filósofos, teólogos, sociólogos, psicólogos e psiquiatras adotaram elementos oriundos do MFF para refletir ou intervir em diversos aspectos da experiência humana (Spiegelberg, 1972, 1982). Interessa ao propósito deste ensaio apontar que algumas apropriações da Fenomenologia repercutiram nos EUA, e na Escola de Chicago, sobretudo pelos trabalhos de Alfred Schutz. Schutz foi um sociólogo austríaco que se apropriou do pensamento de Husserl para desenvolver reflexões na New School for Social Research, em Nova Iorque. As contribuições de Schutz (1970/2012) envolviam críticas aos modelos positivistas de ciência social, por intermédio da elaboração e reflexão de procedimentos descritivos e compreensivos do mundo social, em suas dimensões das relações e comunicações interpessoais, do cotidiano e das imersões em diferentes grupos e contextos sociais.

As ideias de Schutz se tornaram populares na Escola de Chicago, em suas discussões metodológicas de pesquisa qualitativa. Deste modo, nas décadas de 1950-1960, muitos psicólogos se inspiraram na Fenomenologia como novo paradigma de ciência em Psicologia (Wann, 1964; Giorgi, 1970/1978). Foi o pastor holandês Adrian van Kaam (1920-2007) que, em seu doutorado no Western Reserve University, nos EUA, operacionalizou o primeiro modelo de método fenomenológico aplicado às pesquisas sociais em Psicologia (Andrade \& Holanda, 2010), com supervisão parcial de Kurt Goldstein (1878-1965), Abraham Maslow (1908-1970) e Carl Rogers (Spiegelberg, 1972). Conforme explicitado, a Fenomenologia oferecia um método de rigor para refletir a experiência consciente, o que não condiz com a proposta da Psicologia como ciência compreensiva da experiência de outras pessoas. A transposição de um método filosófico que reflete a experiência em primeira pessoa para um método empírico de pesquisa se tornou um problema de investigação (van Kaam, 1959). Ressalta-se que, no final da década de 1950, van Kaam organizara um programa de Mestrado em Psicologia na Duquesne University, com uma orientação em pesquisa fenomenológica (Smith, 2010).

A proposta de van Kaam atraiu a atenção de Giorgi (2012). Em 1958, após se doutorar na Fordhan University, em Nova Iorque, Giorgi estava insatisfeito com as orientações positivistas filosóficas e cientificas da Psicologia estadunidense. Por intermédio de um amigo, padre Edward Hogan (1925-2008), Giorgi (2012) foi apresentado ao trabalho de van Kaam e reconheceu neste uma perspectiva inovadora e alternativa ao positivismo dominante nos EUA. Posteriormente, em 1961, Giorgi se encontrou com van Kaam - que na época substituía Maslow na Brandeis University. Dessa aproximação, Giorgi foi convidado por van Kaam para integrar o corpo de docentes da Duquesne University (Smith, 2010).

Após aceitar o convite e antes de assumir o cargo, Giorgi (2012) começou a participar de diversos cursos de Fenomenologia na New School for Social Research, sob as docências de Alfred Schutz, Rollo May (19091994) e Aron Gurwitsch (1901-1973), e na Universidade de Chicago, sob as regências de Paul Tillich (1886-1965) e Paul Ricouer (1913-2005).

Em 1961, Giorgi assistiu um curso de pesquisa e Fenomenologia ministrado por Johannes Linschoten ${ }^{2}$ (1925-1964), que o convidou para visitá-lo na University of Utrecht (Holanda) e aprofundar estudos sobre pesquisa fenomenológica. Giorgi aceitou o convite e viajou para a Europa, retornando, em 1962, para integrar o programa de Doutorado em Psicologia na Duquesne University e desenvolver um plano metodológico de pesquisa empírica, norteado por uma abordagem fenomenológica (Smith, 2010).

O método fenomenológico empírico (MFE) elaborado por Giorgi (2006), inicialmente, foi aplicado em pesquisas que investigaram vivências de processos de aprendizagem, no entanto se expandiu para investigar outros tipos de vivências. Embora não tenha lecionado na Universidade de Chicago, Giorgi (1979) pode ser considerado como um representante do Zeitgeist inaugurado pela Escola de Chicago. Ressalta-se que, na década de 1960, o legado dessa Escola havia se difundido para outras universidades, originando diversos métodos qualitativos.

\footnotetext{
Sucessor de Frederik Jacobus Johannes Buytendijk (1887-1974), biólogo, filósofo e psicólogo que introduziu a Fenomenologia na Holanda (Spiegelberg, 1972).
} 
Imerso nesse contexto, Giorgi $(1970 / 1978,2012)$ não foi alheio à discussão sobre paradigmas de pesquisa qualitativa nas Ciências Sociais e na Psicologia.

\subsection{Percursos metodológicos}

No Brasil, convém mencionar, outras sistematizações do método fenomenológico empírico (MFE) na pesquisa psicológica foram propostas (Holanda, 2006; Andrade \& Holanda, 2010; DeCastro \& Gomes, 2011). Operacionalizam-se, pois, as seguintes etapas do MFE, com anteparo nos procedimentos elaborados por Giorgi (1997/2008).

1) A suspensão fenomenológica (Epoché) das experiências pessoais e teóricas do pesquisador é o primeiro momento do processo para chegar à compreensão da vivência do sujeito da pesquisa (um termo mais qualitativo para se referir a amostra). Neste ponto, as hipóteses da pesquisa e as teorias que a fundamentam serão retiradas de ação para garantir a livre manifestação do fenômeno investigado, sem manipulá-lo.

2) Em campo, pretende-se obter uma descrição concreta e detalhada das vivências visadas, conforme o cotidiano dos sujeitos investigados. Geralmente, utilizam-se de entrevistas (semiestruturadas ou abertas) como recurso de coleta dos dados descritivos da vivência abordada. Influenciado pelo pensamento de Schutz, Giorgi (1997/2008) considera que o recurso da entrevista é assertivo para facilitar o acesso de uma vivência consciente, manifesta como ato comunicativo que expressa uma idiossincrasia. O prisma metodológico de Giorgi (1997/2008) pressupõe que a pessoa que vivencia - ou já vivenciou - o fenômeno estudado é quem melhor o entende, ao passo que o pesquisador busca aprender com isso. Por isso o emprego da suspensão fenomenológica aludida na etapa anterior.

3) Após a transcrição do material colhido, efetua-se mais uma suspensão fenomenológica do que já é conhecido sobre o fenômeno investigado, para interrogá-lo, como se o acessasse pela primeira vez. Procede-se, ao final da leitura de cada entrevista transcrita, a uma síntese geral do que está sendo percebido e evidenciado por parte do pesquisador.

4) Concluídas as sínteses gerais, retorna-se ao material transcrito, explorando-o com esteio na especificação de suas partes temáticas e evidenciando suas unidades de significação (US). Segundo Giorgi (1997/2008),

No plano operatório, as unidades de significação apropriadas se constituem sob lenta releitura da descrição: cada vez que o pesquisador percebe uma mudança de sentido, ele posiciona a direção, e depois prossegue sua leitura até a unidade de significação seguinte, e assim, sucessivamente (...). As unidades de significação não existem como tais 'nas descrições', mas resultam da atitude e assertividade do pesquisador. (p. 399)
Destarte, localizar uma unidade implica refinar os sentidos elucidados na descrição da vivência pesquisada. Cabe ao pesquisador, portanto, reconhecer que cada descrição está repleta de referências ao cotidiano (senso-comum) do sujeito de pesquisa e elaborar uma descrição condizente a linguagem psicológica articulada em relação ao tema estudado (Giorgi \& Sousa, 2010). Uma vez constituídas, as unidades de significação (US) são examinadas à luz da técnica da variação livre e imaginária, para apreender a essência da tomada de consciência do sujeito pesquisado em relação a sua vivência.

Em síntese, a mencionada técnica consiste em reexaminar as US de todas as entrevistas transcritas, de modo a identificar os sentidos comuns, verificar suas interdependências e organizá-los conforme uma única descrição expressa em termos psicológicos. Esses elementos comuns e transversais a todos os sujeitos pesquisados convergem para o que Giorgi e Sousa (2010) entendem como a estrutura geral (a essência) do fenômeno estudado.

5) Assume-se, finalmente, um posicionamento teórico, que traz à tona tudo o que foi suspendido fenomenologicamente, para formular, em seguida, categorias temáticas à vivência estudada. Esta fase evidencia a intencionalidade (o direcionamento) da consciência do pesquisador sobre o fenômeno pesquisado. Neste ponto, elabora-se uma intelecção condizente à área de conhecimento da pesquisa, para fundamentar o que foi observado em relação à vivência estudada e comunicá-la à comunidade científica.

Em suma, o método fenomenológico empírico (MFE) de Giorgi (1997/2008) considera qualquer fenômeno como algo passível de ser investigado, desde que tornado presente na vivência do sujeito de pesquisa e comunicado ao pesquisador. Essa vivência sustenta e expressa indícios de realidade sobre um determinado mundo social, possível de ser compartilhado e compreendido. Isso acontece pela elucidação das US e essências que manifestam como ocorrem as vivências de um determinado fenômeno (por exemplo, gravidez na adolescência, envelhecimento ou homofobia).

Considera-se que o MFE decorre da inspiração de várias reflexões e posicionamentos filosóficos oriundos da Fenomenologia, repensados numa perspectiva de ciência empírica e qualitativa. A transposição do método fenomenológico filosófico (MFF) para o MFE implica discussões, as quais consideram que esse se distancia daquele, por não assimilar todos os elementos da Filosofia fenomenológica e, logo, se torna válido somente nas querelas da ciência psicológica. Ambas as perspectivas de método fenomenológico, no entanto, assumem a mesma atitude, a qual reconhece que “(...) o sujeito só pode ter sentido em sua relação com o objeto, e, de igual modo, o objeto pressupõe em si o fato de estar ligado à subjetividade" (Giorgi, 1997/2008, p. 389). 


\section{Possíveis interlocuções}

Para cumprir com o objetivo anunciado no início deste ensaio, aborda-se aqui um diálogo entre a análise de conteúdo (AC) e o método fenomenológico empírico (MFE), de modo a explicitar os seus seis principais pontos de interlocução, expressos em seguida.

Primeiro. Os dois métodos são perspectivas elaboradas com base no mesmo Zeitgeist estabelecido, inicialmente, na Escola de Chicago. Isso possibilita o entendimento comum de que a ação humana é significativa seja em suas manifestações verbais, gestuais, escrita etc. Incorre-se, deste modo, a elaboração rigorosa de procedimentos que analisam os significados dessas ações, de forma respeitosa e fiel ao que foi expresso, mas, também, condizente aos ideais e intenções da pesquisa. Logo, a AC (Bardin, 1977/2011) e o MFE (Giorgi, 1997/2008) criticam a concepção clássica de neutralidade em ciência, pois compartilham de um ponto de vista atento para a subjetividade do pesquisador em relação ao objeto de pesquisa, sem renegar a noção de que ela torne se objetiva por procedimentos metodológicos que evitarão interpretações equivocadas (Schwandt, 2003/2006).

Segundo. A AC não se vincula explicitamente a nenhuma abordagem filosófica, todavia é reconhecida como um procedimento analítico de dados oriundos de textos escritos (jornais, diários e entrevistas transcritas, por exemplo) (Bauer, 2000/2005). Ao contrário, o MFE assume explicitamente influência e inspiração em diversos elementos da Filosofia fenomenológica. Por essa razão, o MFE se vincula a uma postura que aborda fenomenologicamente o sujeito em diversos contextos, inclusive na entrevista (Gomes, 1998). Assim como na AC, entretanto, o MFE necessita de um texto escrito para incidir seus procedimentos analíticos.

Terceiro. Em cada método de pesquisa, urge uma formação do pesquisador para aprender a reconhecer as manifestações do seu objeto de estudo em campo e no texto analisado. Por exemplo, um psicanalista é formado para perceber as manifestações do inconsciente na fala, nos gestos e nos sonhos do sujeito analisado; posteriormente, analisa-se o que foi percebido, segundo os princípios da Psicanálise. A mesma lógica ocorre em relação a AC e MFE. Na AC, o pesquisador refina sua percepção para aprender a observar e analisar o seu objeto de estudo como uma mensagem a ser explicitada, conforme um rigor metodológico. No método fenomenológico empírico (MFE), o objeto de estudo é abordado como um fenômeno que se manifesta de acordo com a vivência a ser compreendida, segundo os procedimentos do método. Destarte, a forma como os métodos retrocitados concebem o seu objeto de estudo difere em termos de concepção.

Quarto. Ambos os métodos solicitam leitura geral do texto, antes de iniciar a análise propriamente dita. Bardin (1977/2011) estabelece a leitura flutuante como uma atividade que consiste em situar o primeiro contato do pes- quisador com o material coletado, de modo “(...) a analisar e conhecer o texto deixando-se invadir por impressões e orientações. (...) Pouco a pouco, a leitura vai se tornando mais precisa, em função de hipóteses emergentes, da projeção de teorias mais adaptadas sobre o material" (p. 126). Giorgi (1997/2008), de modo semelhante, sugere leitura global do texto, com o fim de perceber como suas partes são compostas para, posteriormente, abordá-las de maneira mais detalhada.

Quinto. Os dois métodos analisam o texto, dividindo-o em unidades. O que varia é a forma como cada procedimento concebe e trata a unidade. A análise de conteúdo (AC) entende os segmentos de conteúdos no texto como as unidades de registro (UR) mais pertinentes aos objetivos da pesquisa. As UR são estabelecidas previamente em termos de palavra, tema, personagem, acontecimento e documento (Bardin, 1977/2011). Estes tipos de unidades deverão ser indicados no texto e visarão à codificação, à contagem frequencial e à fundamentação da inferência. No MFE, as unidades são concebidas como unidades de significação (US). Estas, via de regra, são analisadas por temas e não palavras, unidades gramaticais ou frases, pois esses componentes são insuficientes para expressar a totalidade do que a consciência intenciona na vivência pesquisada, além de dificultar a percepção da mudança de uma US para outra (Giorgi, 2006).

Sexto. Embora ambos os métodos proponham a elaboração de categorias, eles diferem em relação ao anteparo empírico que norteia o processo de categorização. Na AC, as unidades são medidas pela sua frequência de aparição ou ausência no texto. De acordo com o que foi codificado e inferido nas UR levantadas, elaboram-se categorias. No MFE, não há a preocupação de medir e codificar as US. Cabe ao pesquisador mapear as aparições de cada US e definir sua essência, pela técnica de variação livre e imaginária; posteriormente, elaboram-se categorias. Com efeito, este último ponto de interlocução complementa o que foi exposto no primeiro ponto, em relação ao rigor pretendido para evitar interpretações equivocadas.

\section{Considerações finais}

No transcurso das exposições teóricas procedidas, observou-se neste estudo uma série de considerações relativas às interlocuções de a análise de conteúdo (AC) com o método fenomenológico empírico (MFE), sob o argumento de que ambos são frutos do mesmo Zeitgeist metodológico. Pretendeu-se, de forma abreviada, demonstrar como esse Zeitgeist se desenvolveu na Escola de Chicago e como os procedimentos da AC e do MFE incorporaram suas reivindicações. Dissertados os percursos históricos e metodológicos de cada método, o estudo assinalou os seguintes pontos de interlocução, a saber: (1) a ênfase na ação humana investida de significados como crítica à neutralidade científica; (2) a vinculação filosófica; (3) a 
forma de concepção e tratamento do objeto de estudo; (4) a questão do primeiro contato com o material transcrito; (5) a divisão do texto em unidades analíticas; e (6) o anteparo empírico que norteia o processo de categorização.

É de se reconhecer que o campo das Ciências Sociais e Humanas (representado pela Sociologia, Antropologia, Psicologia, Educação, Linguística etc.) é constituído por uma diversidade de perspectivas metodológicas, por vezes utilizadas em disciplinas diferentes. Tal variedade requer dos pesquisadores desse campo, fundamental e constantemente, revisões e elucidações epistêmicas sobre os seus modos de fazer pesquisa.

Aponta-se a ideia de que outras pesquisas do mesmo caráter podem ser realizadas, por exemplo, entre a AC e o método da teoria fundamentada (grounded theory) - outro desdobramento da Escola de Chicago - ou entre o MFE e a análise do discurso. Considera-se, pois, que o exercício comparativo entre distintos métodos de pesquisa qualitativa é um trabalho profícuo de debate teórico, que clarifica e torna mais complexo o debate sobre as delimitações metodológicas das Ciências Sociais e Humanas.

Pondera-se acerca de que, no Brasil, há uma escassez de comparações entre a AC e o MFE, de modo que este ensaio teórico-comparativo versou a tentativa inicial de propor uma pauta para diálogo entre esses métodos, respeitando suas cercanias epistêmicas. Com intento de reunir mais avanços, lançam-se as seguintes provocações: é possível, atualmente, utilizar elementos da AC no MFE e vice-versa? Ambos os métodos podem contribuir um com o outro?

\section{Referências}

Andrade, C. \& Holanda, A. (2010). Apontamentos sobre pesquisa qualitativa e pesquisa empírico-fenomenológica. Estudos de Psicologia (Campinas), 27(2), 259-268.

Bardin, L. (2011). Análise de conteúdo (3a ed., L. Pinheiro, Trad.). São Paulo: Edições 70. (Trabalho original publicado em 1977).

Bauer, M. W. (2005). Análise de conteúdo clássica: uma revisão. In M. Mauer \& G. Gaskell (eds.), Pesquisa qualitativa com texto, imagem e som: um manual prático (4a ed., p. 189-217., P. Guareschi, Trad.). Petrópolis: Vozes. (Trabalho original publicado em 2000).

Boava, D. \& Macedo, F. (2011). Contribuições da fenomenologia para os estudos organizacionais. Cadernos EBAPE [online], vol. 9, supl.esp [citado em 28 janeiro, 2013], p. 469-487. Disponível em: http://www.scielo.br/pdf/cebape/v9nspe1/ v9nspe1a03.pdf

Caregnato, R. \& Mutti, R. (2006). Pesquisa qualitativa: análise do discurso versus análise de conteúdo. Texto \& Contexto Enfermagem, 15(4), 679-684.

DeCastro, T. \& Gomes, W. (2011). Movimento fenomenológico: controvérsias e perspectivas na pesquisa psicológica. Psicologia: Teoria e Pesquisa, 27(2), 233-240.
Denzin, N. \& Lincoln, Y. (2006). A disciplina e a prática da pesquisa qualitativa. In N. Denzin \& Y. Lincoln (orgs.), $O$ planejamento da pesquisa qualitativa: teorias e abordagens (2a ed., p. 15-41., S. Netz, Trad.). Porto Alegre: Artmed. (Trabalho original publicado em 2003).

Giorgi, A. (1978). A Psicologia como ciência humana: uma abordagem de base fenomenológica. Belo Horizonte: Interlivros. (Trabalho original publicado em 1970).

Giorgi, A. (1979). The relationship among level, type, and structure and their importance for social science theorizing: a dialogue with Schütz. In A. Giorgi., R. Knowles, \& D. Smith (eds.), Duquesne studies in phenomenological psychology III (p. 81-96). Pittsburgh, PA: Duquesne University Press.

Giorgi, A. (2006). Difficulties encountered in the application of the phenomenological method in the social sciences. Análise Psicológica, 3(XXIV), 353-361.

Giorgi, A. (2008). Sobre o método fenomenológico utilizado como modo de pesquisa qualitativa nas ciências humanas: teoria, prática e avaliação. In Vários autores, A pesquisa qualitativa: enfoques epistemológicos e metodológicos (p. 386409., A. Cristina, Trad.). Petrópolis, RJ: Vozes. (Trabalho original publicado em 1997).

Giorgi, A. \& Sousa, D. (2010). Método fenomenológico de investigação em psicologia. Lisboa: Fim de Século.

Giorgi, A. (2012). Amedeo Giogi interviewed by former students [citado em 26 Janeiro, 2013]. Disponível em: http://www. newexistentialists.com/posts/07-10-12

Gomes, W. B. (1998). A entrevista fenomenológica e o estudo da experiência consciente. In W. B. Gomes (org.), Fenomenologia e pesquisa em Psicologia (p. 19-44). Porto Alegre: UFRGS.

Goto, T. A. (2008). Introdução à Psicologia fenomenológica: a nova Psicologia de Edmund Husserl. São Paulo: Paulus.

Hammersley, M. (2000). Taking sides in social research: essays in partisanship and bias. London: Routledge.

Heidbreder, E. (1981). Psicologias do século XX (L. Blandy, Trad.). São Paulo: Mestre Jou (Trabalho original publicado em 1933).

Holanda, A. F. (2006). Questões sobre pesquisa qualitativa e pesquisa fenomenológica. Análise psicológica, 3(XXIV), 363-372.

Husserl, E. (2006). Ideias para uma fenomenologia pura e para uma filosofia fenomenológica: introdução geral à fenomenologia pura (2a ed., M. Susuki, Trad.). Aparecida, SP: Ideias \& Letras. (Originalmente publicado em 1913).

Hycner, R. H. (1985). Some guidelines for the phenomenological analysis of the interview data. Human Studies, 8, 279-303.

Marx, M. \& Hillix, W. (1976). Sistemas e teorias em Psicologia. São Paulo: Cultrix (Trabalho original publicado em 1963).

Oliveira, D. C. (2008). Análise de conteúdo temático-categorial: uma proposta de sistematização. Revista Enfermagem (UERJ), 16(4), 569-576. 
Penna, A. G. (2000). Introdução à epistemologia. Rio de Janeiro: Imago.

Penna, A. G. (2001). Introdução à Psicologia fenomenológica. Rio de Janeiro: Imago.

Pires, A. (2008). Sobre algumas questões epistemológicas de uma metodologia geral para as ciências sociais. In Vários autores, A pesquisa qualitativa: enfoques epistemológicos e metodológicos (p. 43-94, A. Cristina, Trad.). Petrópolis, RJ: Vozes (Trabalho original publicado em 1997).

Puglisi, M. \& Franco, B. (2005). Análise do conteúdo (2a ed.). Brasília: Liber Livro.

Rocha, D. \& Deusdará, B. (2005). Análise de conteúdo e análise do discurso: aproximações e afastamentos na (re)construção de uma história. Alea, 7(2), 305-322.

Rogers, C. R. (1992). Terapia centrada no cliente (M. J. Ferreira, Trad.). São Paulo: Martins Fontes. (Trabalho original publicado em 1951).

Schultz, D. \& Schultz, E. (2007). História da psicologia moderna (8a ed., S. Cuccio, Trad.). São Paulo: Thomson Learning. (Trabalho original publicado em 1972).

Schutz, A. (2012). Sobre fenomenologia e relações sociais (R. Weiss., Trad.). Petrópolis: Vozes. (Trabalho original publicado em 1970).

Schwandt, T. (2006). Três posturas epistemológicas para a investigação qualitativa: interpretativismo, hermenêutica e construcionismo social. In N. Denzin \& Y. Lincoln (orgs.), $O$ planejamento da pesquisa qualitativa: teorias e abordagens (2a ed., p. 193-217., S. Netz, Trad.). Porto Alegre: Artmed. (Trabalho original publicado em 2003).

Sibley, E. (2011). Social science research council: the first fifty year [online, citado em 23 Janeiro, 2013]. New York: Social science research council. Disponível em: http://www.ssrc.org/ workspace/images/crm/new_publication_3/\%7B1f20c6e1565f-de11-bd80-001cc477ec70\%7D.pdf

Smith, D. (2010). A history of Amedeo P. Giorgi's Contributions to the Psychology Department and Phenomenology Center of Duquesne University in his Twenty-Four Years There. Cercle interdisciplinaire de recherches phénoménologiques [online], vol. 1, édition spéciale [citado em 20 Julho, 2013], p. 249-265. Disponível em: http://www.cirp.uqam. ca/CIRP/22-Smith.pdf

Spiegelberg, H. (1972). Phenomenology in Psychology and Psychiatry. Evaston: Northwestern University Press.

Spiegelberg, H. (1982). The phenomenological movement: a historical introduction (3a ed). Boston: Martinus Nijhoff Publisher.

Van Kaam, A. (1959). Phenomenal analysis: exemplified by a study of the experience of 'really feeling understood'. Journal of Individual Psychology, 15(1), 66-72.

Vidich, A. \& Lyman, S. (2006). Métodos qualitativos: sua história na sociologia e na antropologia. In N. Denzin \& Y. Lincoln (orgs.), O planejamento da pesquisa qualitativa: teorias e abordagens (2a ed., p. 49-90., S. Netz, Trad.). Porto Alegre: Artmed. (Trabalho original publicado em 2003).
Wann, T (Ed.). (1964). Behaviorism and phenomenology: contrasting bases for modern psychology. Chicago: University of Chicago Press.

Worceter, K. (2001). Social science research council, 1923-1998 [online, citado em 29 Janeiro, 2013]. New York: Social science research council. Disponível em: http://www.ssrc.org/ workspace/images/crm/new_publication_3/\%7B1f20c6e1565f-de11-bd80-001cc477ec70\%7D.pdf.

Paulo Coelho Castelo Branco - Docente do Curso de Psicologia do Instituto Multidisciplinar em Saúde da Universidade da Bahia (UFBA), Campus Anísio Teixeira - Vitória da Conquista. Doutorando em Psicologia Social pela Universidade Federal de Minas Gerais (UFMG). Mestre em Psicologia, concentração em Psicanálise, Práticas Clínicas e Epistemologia das Psicologias, pela Universidade Federal do Ceará (UFC). Graduado em Psicologia pela Universidade de Fortaleza (UNIFOR).E-mail:pauloccbranco@gmail.com

Recebido em 12.08.2013 Primeira decisão editorial em 02.12.2013 Aceito em 10.10.2014 